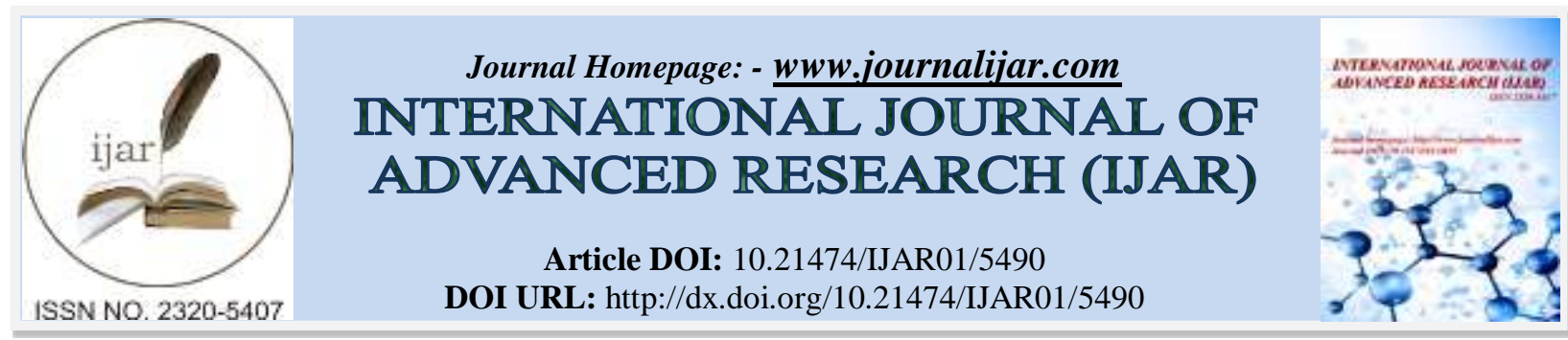

RESEARCH ARTICLE

\title{
CHARACTERIZATION OF SILTY SAND IN VIEW OF ITS USE IN ROAD CONSTRUCTION AND SPORTING TRACTS.
}

\author{
Codjo Luc Zinsou ${ }^{1}$, Ezechiel Alloba ${ }^{1}$, Dègla Rodolphe Amoussou ${ }^{1}$ And ${ }^{*}$ François Ngapgue ${ }^{2}$. \\ 1. Abomey-Calavi Advanced School of Engineering, Abomey-Calavi, Benin. \\ 2. FOTSO Victor University Institute of Technology, University of Dschang, Cameroon.
}

\section{Manuscript Info}

-

Manuscript History

Received: 21 July 2017

Final Accepted: 23 August 2017

Published: September 2017

Key words:-

Local materials, lime, silty sand, optimum dosage, base course, surface course.

\section{Abstract}

The present study is inscribed within the framework of the valorization of local materials in road construction techniques. Identification tests were carried out on silty sand. The results obtained showed that the content of fine particles, the CBR at 95\% Modified Optimum Proctor and the plasticity index of the samples studied were respectively $15.25 \%, 31$ and $16 \%$. From the results obtained, it is evident that these materials cannot be used in their natural state for the construction of road infrastructures and sporting tracts. A proposal for the correction of these materials by adding $2 \%, 3 \%, 4 \%, 6 \%$ and $8 \%$ of lime was carried out. Test results carried out on samples of the modified materials showed that, by adding $4 \%$ lime and taking construction dispositions, these materials are good for usage as base course in road construction and as surface course in sporting tracts.

Copy Right, IJAR, 2017,. All rights reserved.

\section{Introduction:-}

Nowadays, the stabilization of soils by adding lime in view of improving their performances for usage in road construction is a widely used technique. By 1957, athletic tracts, football training pitches and back playgrounds were realized with materials stabilized with industrial wastes, crushed or grinded natural rocks. These materials being the principal constituents are mixed with other elements like clay, calcium sulfate, sandy clay, grinded calcareous materials and of calcium sulfates to render the final layer cohesive.

Lime is widely used for improving the foundation and base courses for roads, for the construction of railway lines and airport tarmacs. Meanwhile only few scientific works have made allusion of the need of this technique in the area of sporting infrastructures.

The construction of sporting tracts with synthetic layers results in huge investments. It is therefore important to know which material to use for the base course in order to assure along life span for these tracts. It is equally necessary to look for alternative solutions faced with the very high cost of synthetic layers.

* Address correspondence to this author at the FOTSO Victor University Institute of Technology, University of Dschang, Cameroon Tel: +237-699547394; fgapguefcr@gmail.com 
To this effect, it is imperative to carry out a prospection of available materials whose characteristics can respond to the criteria of soils used for sporting infrastructures irrespective of their state (natural or modified).

To carry out this study, we have chosen silty sand which is one of the materials often used for embankment despite its poor physical characteristics. The objective of the present study is the characterization of silty sand and the elaboration of proposals in view of its better usage in the construction and maintenance of sporting tracts. The sample of silty sand used for this study was collected from Ahouicodji in the Ouidah Council (Benin).

\section{Materials and Methods:-}

The grain distribution test was carried out using sieve analysis according to NF P 18-560 standard [1] for particles of dimension above $0.080 \mathrm{~mm}$. The sedimentation test according to the norm NF P 94-057 [2] test was carried out for particles of dimension less than $0.080 \mathrm{~mm}$.

The liquid limit was determined using the Casagrande apparatus while the plastic limit was determined using the rolling method according to the norm NF P 94-051 [3]. The plasticity index was calculated as the difference between liquid and plastic limits.

The sand equivalent was determined by the washing method using plexiglass tubes and the apparatus for sand equivalent test according to the norm NF P 18-597 [4].

The organic content of materials studied was determined by the use of sulfochromic dosage method, according to norm NF ISO 14235 [5].

The Modified Proctor optimum was determined by compaction of the samples in the Modified Proctor mould that allowed to obtain the optimal water content and the maximum dry density in accordance with the norm NF P 94-093 [6].

The CBR was determined by compaction in a CBR mould in accordance with the norm NF P 94-078 [7] that allowed obtaining the load that the material can carry without rupturing.

\section{Results and Interpretation:-}

Physical characteristics of silty sand:-

The particle size distribution, sand equivalent, Atterberg limits, plasticity index as well as the organic matter content of the sitly sand obtained are presented on table 1. The particle size distribution curve of the silty sand studied is also presented on figure 1.

Table 1:- Physical characteristics of natural soil samples

\begin{tabular}{|l|l|l|}
\hline CHARACTERISTICS & CHARACTERISTICS VALUES \\
\hline \multirow{4}{*}{$\begin{array}{l}\text { Particle size distribution : } \\
\text { Proportion passing through the } \\
\text { sieve }\end{array}$} & $2 \mathrm{~mm}(\%)$ & 100 \\
\cline { 2 - 3 } & $1,25 \mathrm{~mm}(\%)$ & 99,28 \\
\cline { 2 - 3 } & $0,40 \mathrm{~mm}(\%)$ & 70,24 \\
\cline { 2 - 3 } & $0,315 \mathrm{~mm}(\%)$ & 43,36 \\
\cline { 2 - 3 } Sand equivalent & $0,149 \mathrm{~mm}(\%)$ & 20,64 \\
\hline Atterberg limits & $\mathrm{ES}(\%)$ & 15,28 \\
\hline & $\mathrm{W}_{\mathrm{L}}(\%)$ & 22 \\
\cline { 2 - 3 } & $\mathrm{W}_{\mathrm{P}}(\%)$ & 40 \\
\cline { 2 - 3 } & $\mathrm{IP}$ & 24 \\
\hline Organic matter & $\mathrm{OM}(\%)$ & 16 \\
\hline \multirow{3}{*}{ Classification } & $\mathrm{HRB}$ & 0.8 \\
\cline { 2 - 3 } & LCPC & Silty clayey sand \\
\hline
\end{tabular}




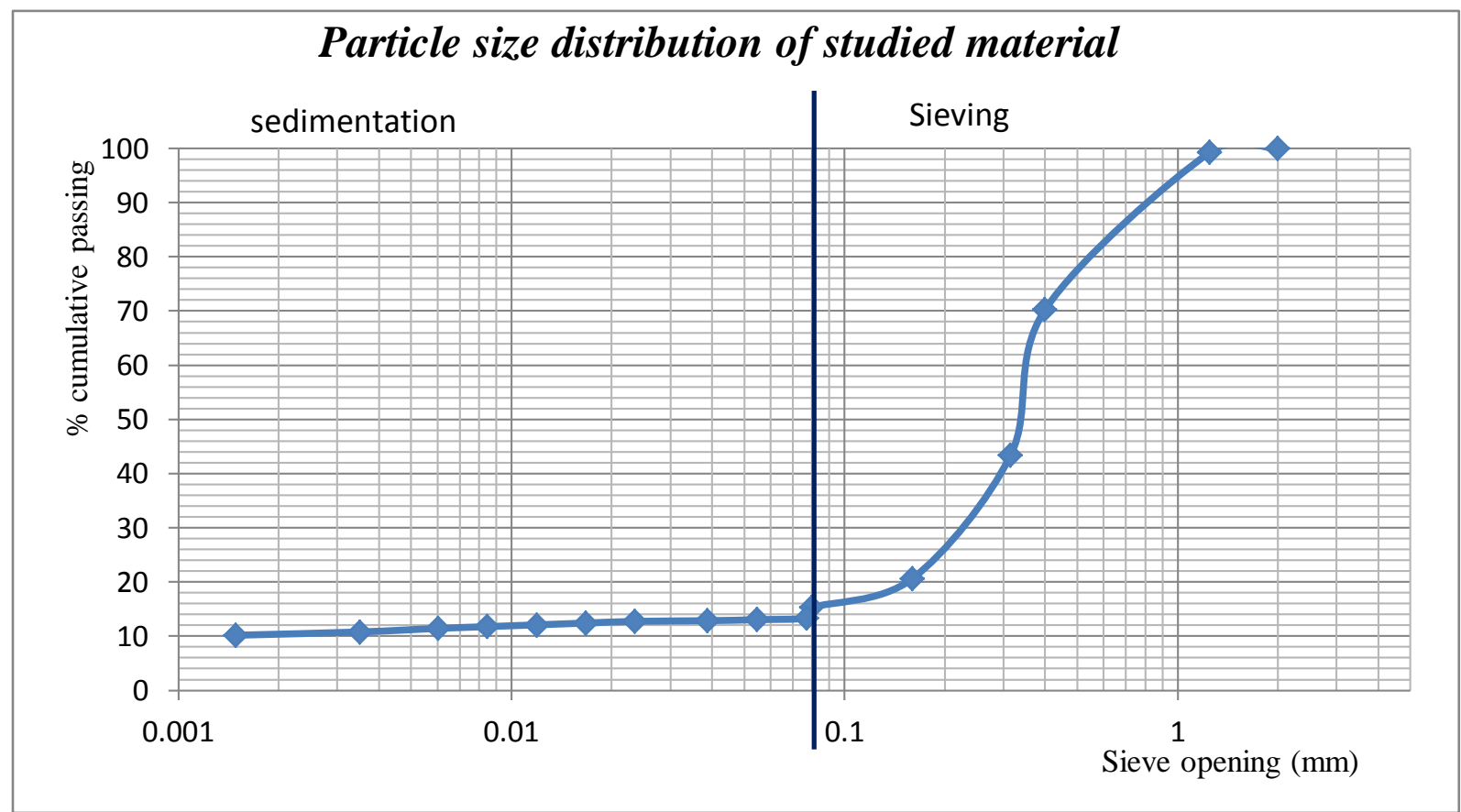

Fig. (1):- Particle size distribution curve of studied material

Table 1 shows that particles passing through the $0.08 \mathrm{~mm}$ sieve make up $15.28 \%$, which implies $84.72 \%$ of the particles have dimensions of above $0.08 \mathrm{~mm}$. In addition, $50 \%$ of particles of dimension above $0,080 \mathrm{~mm}$ passed through the $2 \mathrm{~mm}$ sieve (table 2 and figure 1). The values of the liquid limit and plasticity index are $40 \%$ and $16 \%$ respectively. According to the LCPC classification [8], the sample studied is plastic silt (class LP). Table 1 equally shows that, less than $35 \%$ of the particles have dimensions less than $0,080 \mathrm{~mm}$. The material studied is silty clayey sand (class A-2-6 according to HRB classification).

\section{Compaction characteristics of the natural sample:-}

The compaction characteristics of the natural sample are presented on figures 2, 3 and table 2.

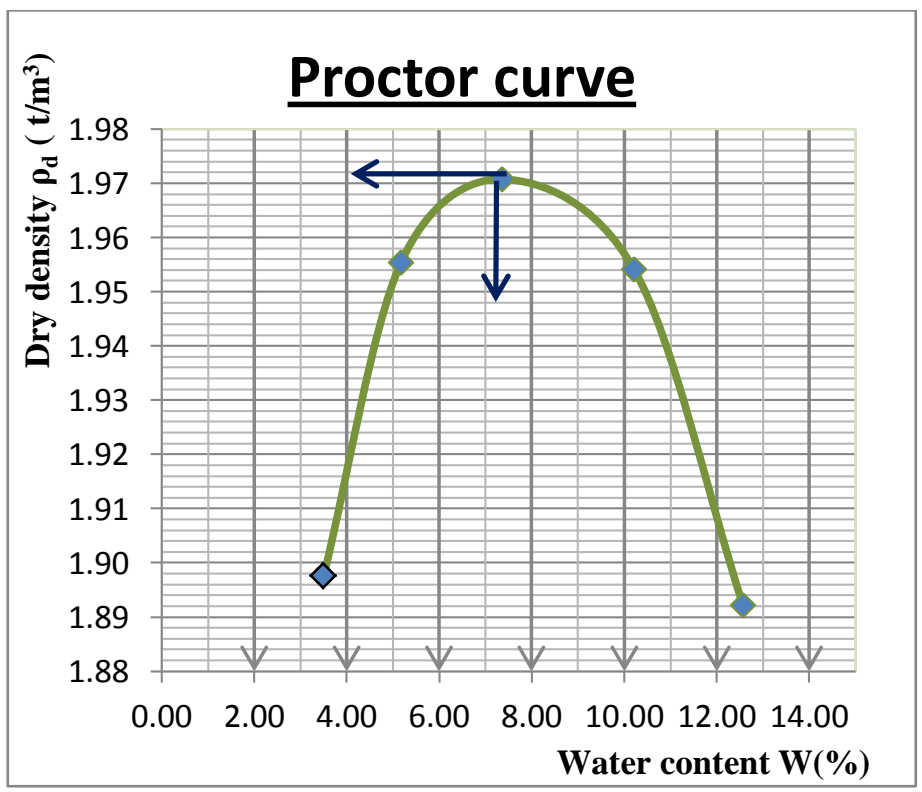

Fig. (2):- Proctor Curve of silty sand 


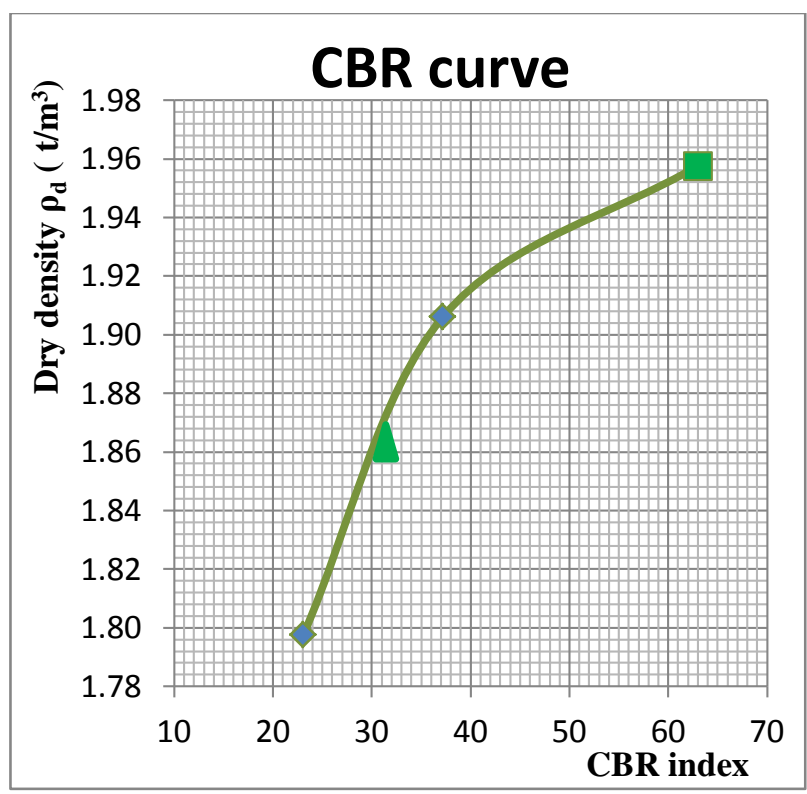

Fig. (3):- CBR Curve of silty sand.

Table 2:- Compaction characteristics of the natural sample

\begin{tabular}{|l|l|l|}
\hline \multicolumn{2}{|l|}{ Characteristics } & Characteristics values \\
\hline \multirow{3}{*}{ Modified Proctor Optimum } & $\rho_{\text {dmax }}\left(\mathrm{t} / \mathrm{m}^{3}\right)$ & 1.97 \\
\cline { 2 - 3 } IBR (Immediate Bearing Ratio) & $\mathrm{W}_{\text {opt }}(\%)$ & 7.21 \\
\hline \multirow{4}{*}{ CBR after 96 hours imbibition } & $95 \%$ OPM & 28 \\
\hline & CBR at $100 \%$ MOP & 63 \\
\cline { 2 - 3 } & CBR at 95\% MOP & 31 \\
\cline { 2 - 3 } & Swelling $(\%)$ & 0.1 \\
\cline { 2 - 3 } & Water content after imbibition & Within 11,1 and 12,25 \\
\hline
\end{tabular}

Figure 1 and table 2 show that the maximum dry density and the optimum water content of the natural sample are $1,97 \mathrm{t} / \mathrm{m}^{3}$ and $7,21 \%$ respectively.

Concerning mechanical characteristics, the immediate bearing ratio (IBR) value of material is 28 at $95 \%$ MOP, which is insufficient for the stability of the sample (the IBR minimal allowable value is 50). The CBR is 31 at $95 \%$ MPO (Modified Proctor Optimun), which is also insufficient for the base course (the minimal allowable value is 80) and as a surface course but may be acceptable for the foundation course (the minimal allowable value is 30 ). With consideration of the above cited exigencies, it is clear that the studied material sample in its natural state can neither be used for base nor surface courses in sporting tracts despite the fact that it presents certain characteristics in conformity with the exigencies of a tract. For such materials, treatment by the use of hydraulic binders in view of improving its mechanical properties and its resistance is necessary. Lime was proposed for the present study.

\section{Mechanical performances of the treated material:-}

Proctor Optimum and CBR of treated materials:-

The Proctor Optimum and CBR of treated materials are presented on figures 4, 5, 6, 7 and 8 . 

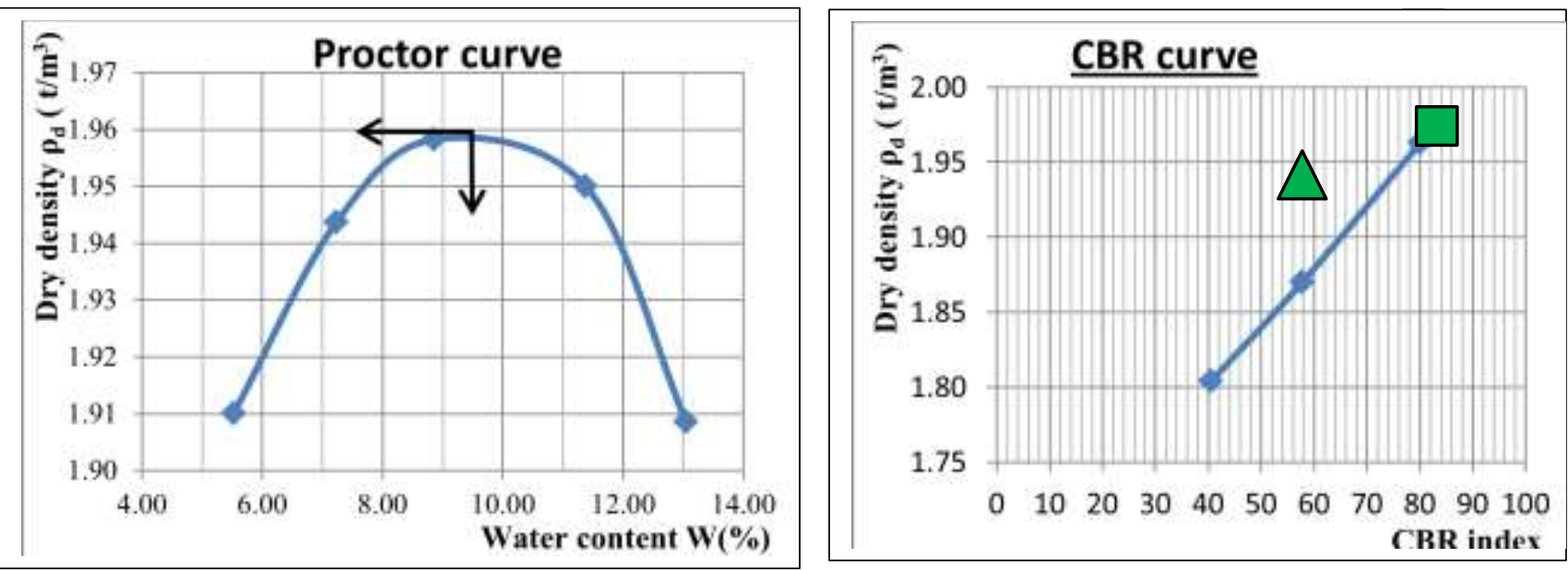

Fig. (4):- Proctor and CBR curves of silty sand treated with $2 \%$ lime
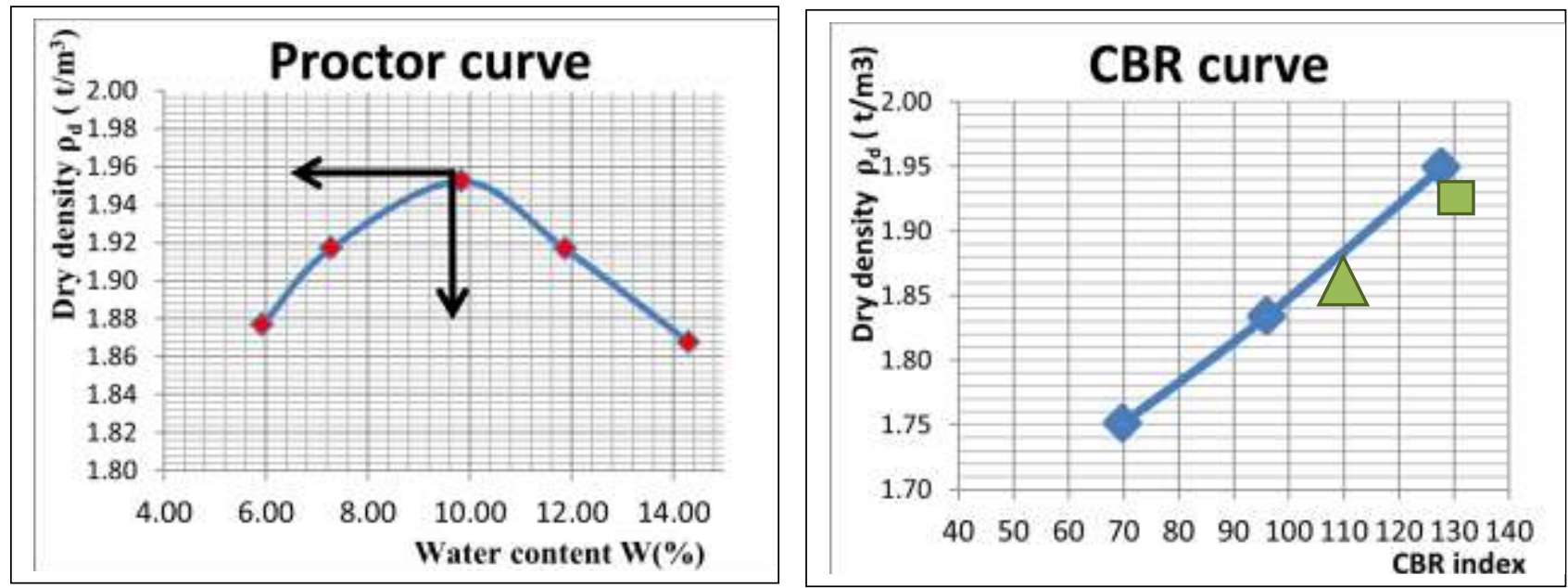

Fig. (5):- Proctor and CBR curves of silty sand improved with 3\% lime.
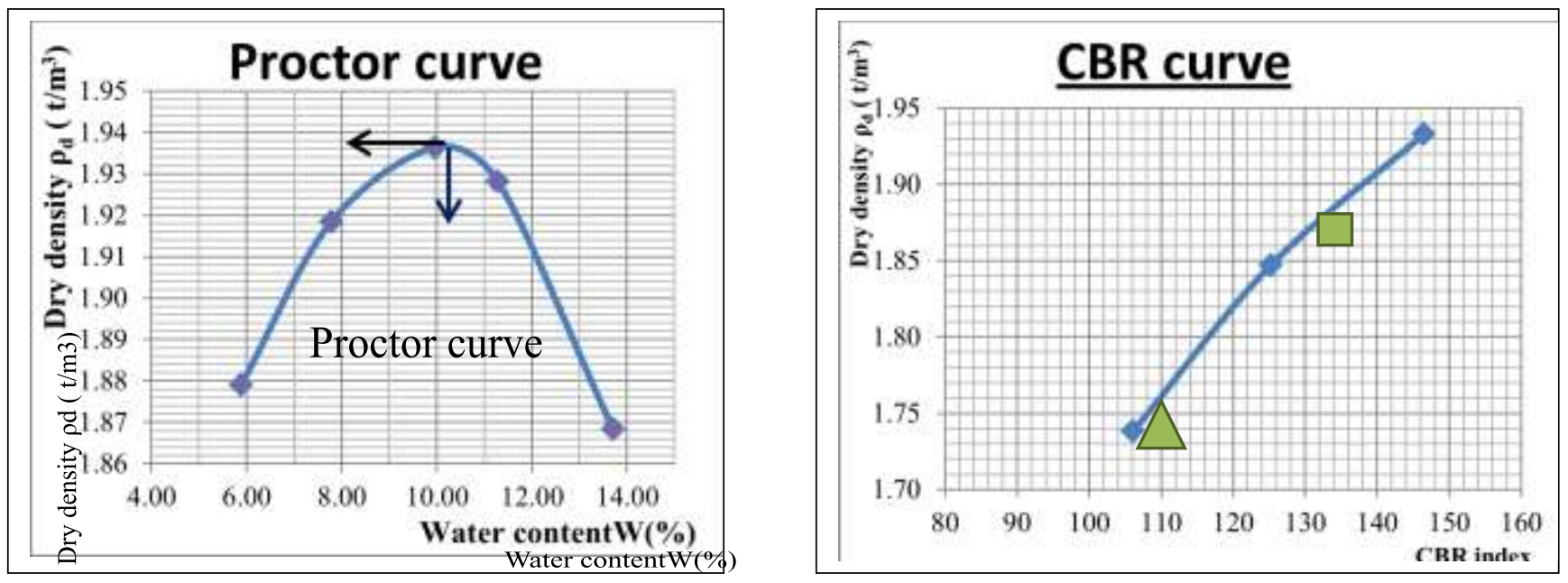

Fig. (6):- Proctor and CBR curves of silty sand improved with $4 \%$ lime. 

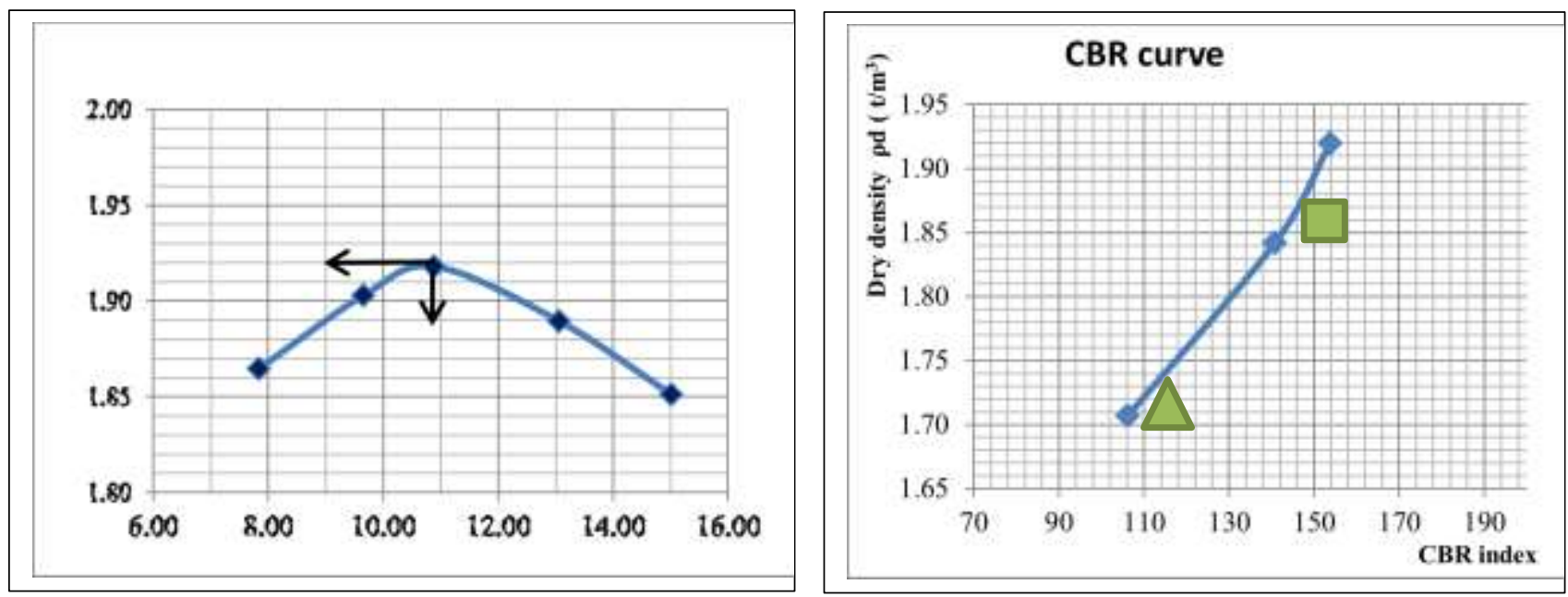

Fig. (7):- Proctor and CBR curves of silty sand improved with 6\% lime.
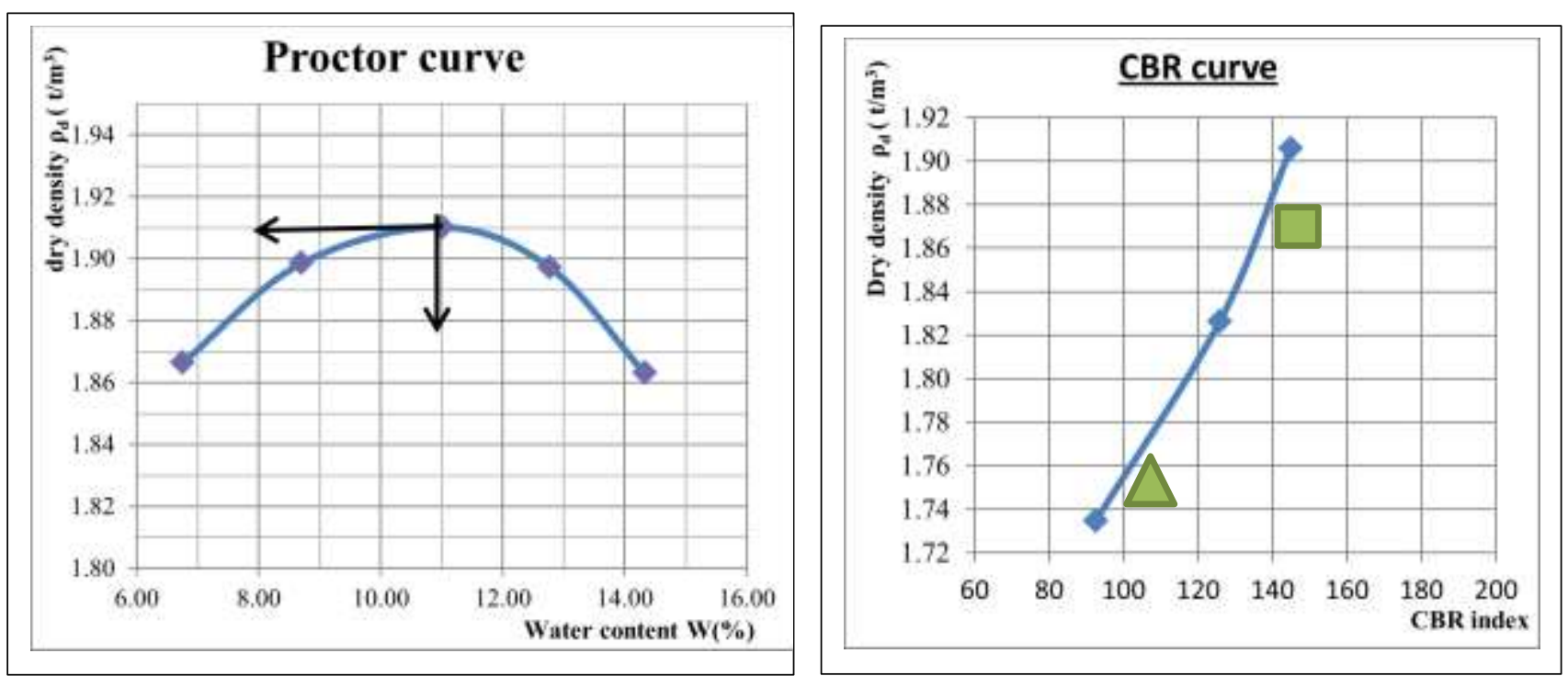

Fig. (8):- Proctor and CBR curves of silty sand improved with $8 \%$ lim Influence of the proportion of lime on the optimum dry density, the optimal water content and the CBR:The evolution of the dry density, the optimal water content and the CBR with the proportion of lime is presented on figures 9,10 and 11 .

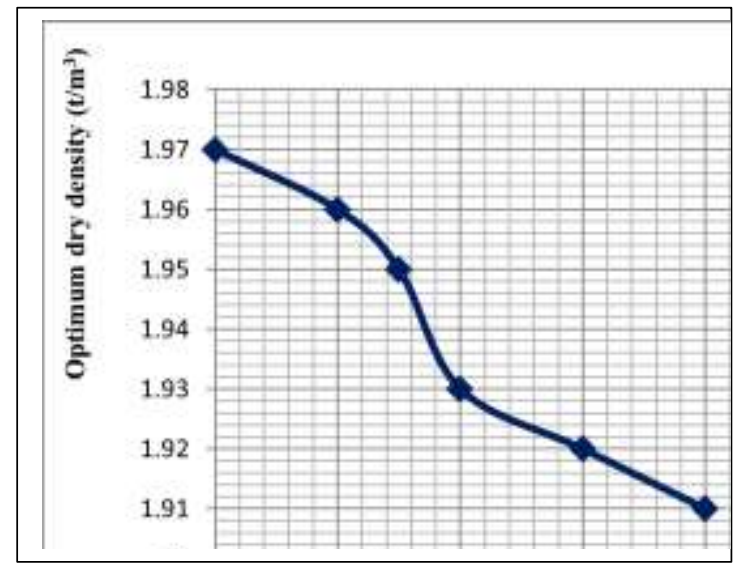

Fig. (9):- Evolution of the dry density with the percentage of lime.

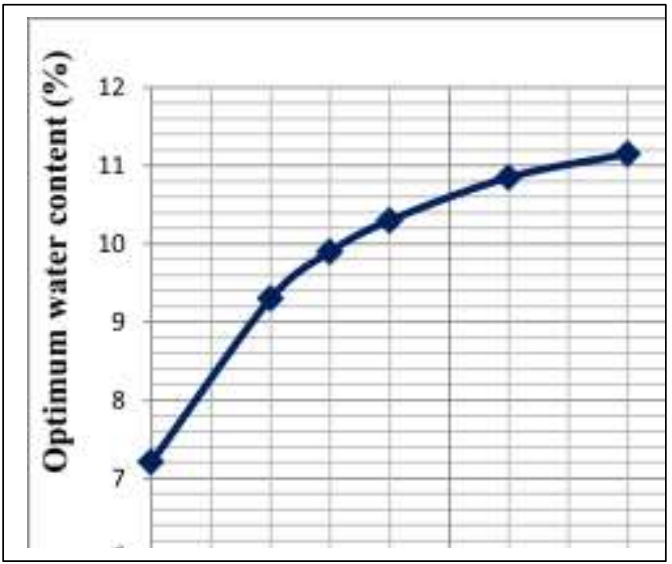

Fig. (20):- Evolution of the optimum water content with lime content 


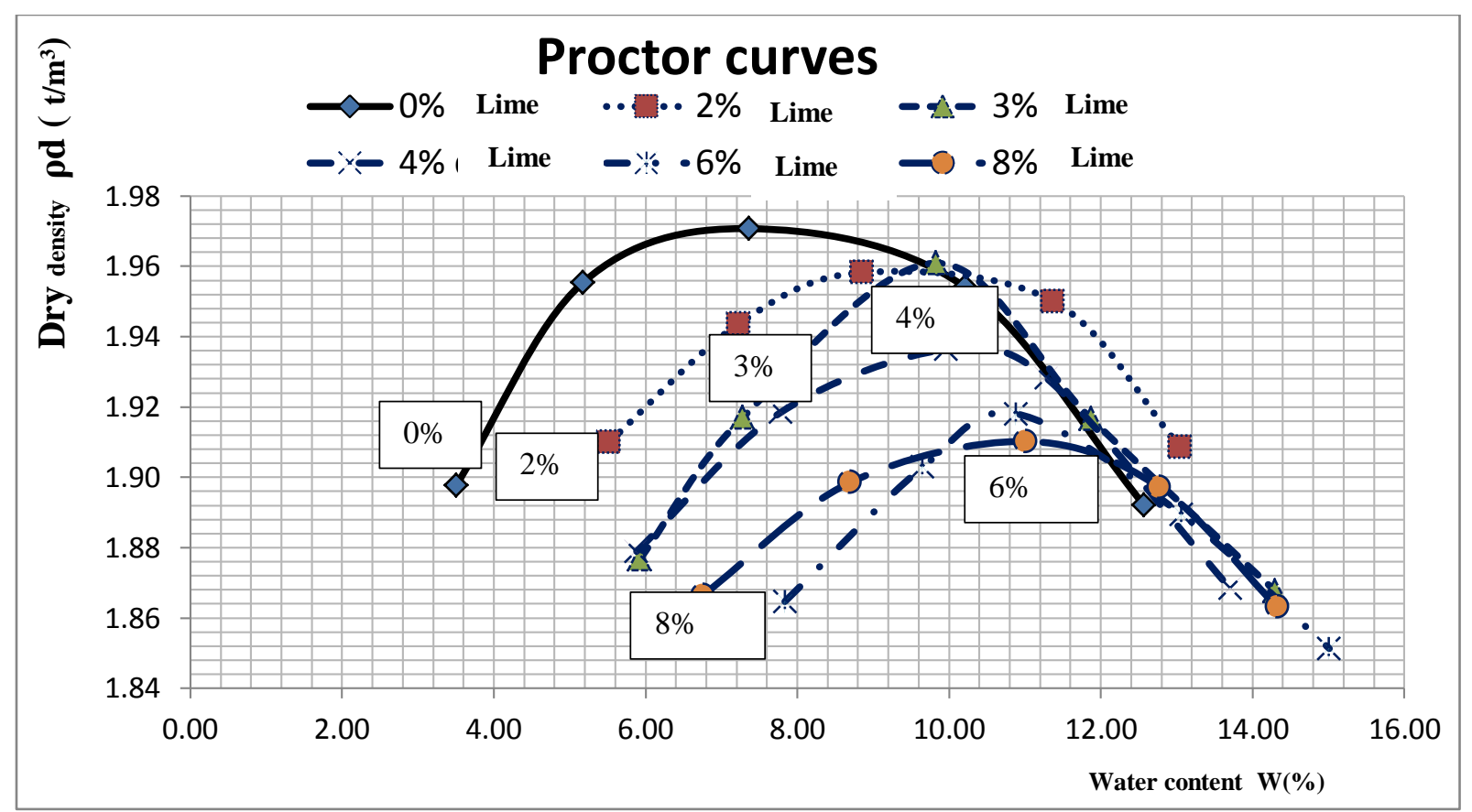

Fig. (31):- Influence of lime content on dry density and water content

It is observed that as the quantity of lime increases, the optimum water content increases correspondingly which reduces the dry density. The Proctor curve starts below and on the right of the curve of the natural material. It is equally noted that the IBR and CBR increase with the dosage of lime up to $6 \%$ before decreasing. This reduction of IBR and CBR values indicates that the quantity of lime in the mixture was already enough. The increase of the IBR confirms that the silty sand studied becomes more stable (IBR $>50)$ as the dosage in lime increases. Concerning the Atterberg limits, it is observed that the liquid limit increases with the percentage of lime. The plastic limit increases rapidly compared to the liquid limit, which lead to the reduction of the plasticity index. The soil swelling which was $0.06 \%$ drops to $0.002 \%$ at $8 \%$ lime content. It is worth noting that if the particle size distribution of the lime is not respected, an explosion of the test sample is observed.

It is observed that the compressive and traction strength increase with respect to the age and the lime content in the sample. In this light, it can be induced that the lime has improved the mechanical properties of the studied material (figure 12). Improving of soils with lime is a technique which seeks the improvement of mechanical characteristics of the material at long term rather than at a short term. Therefore the mechanical characteristics of the material obtained shall be more improved with time.
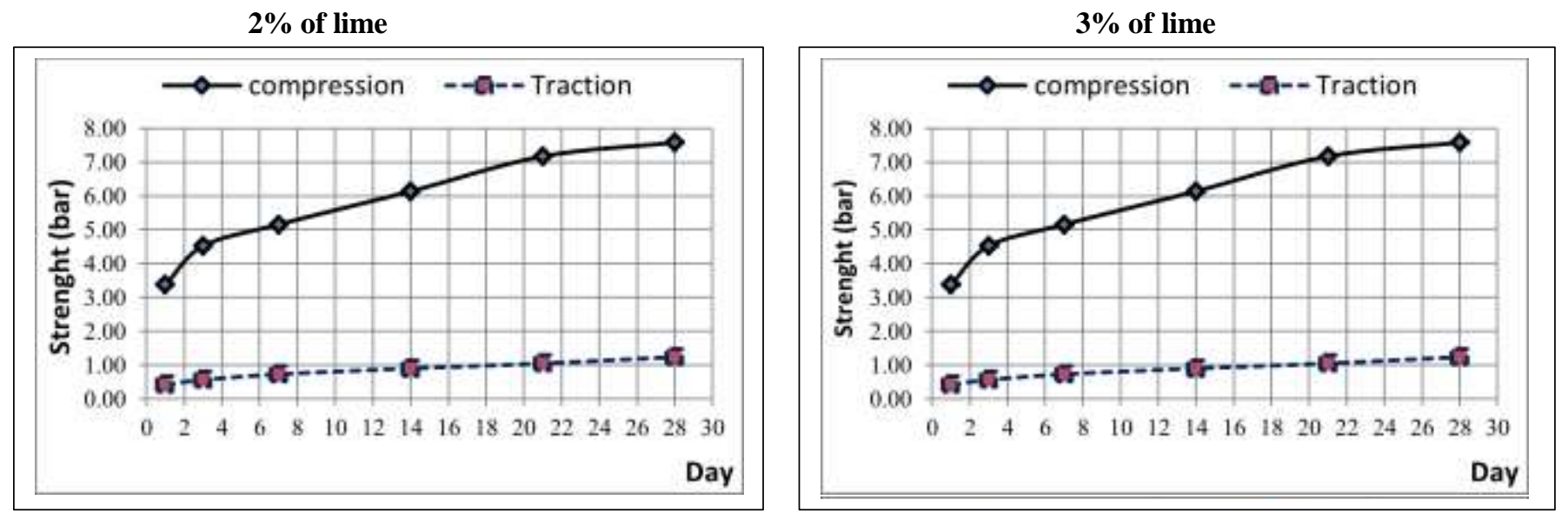
$8 \%$ of lime

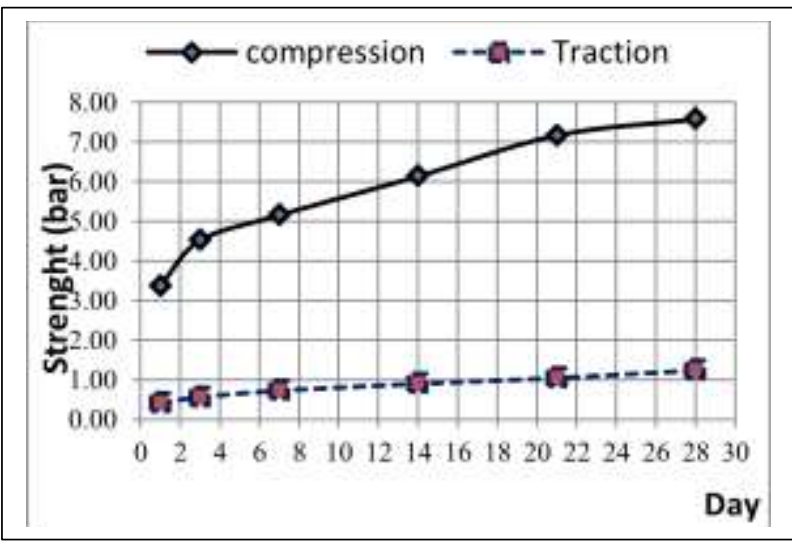

$\%$ of lime

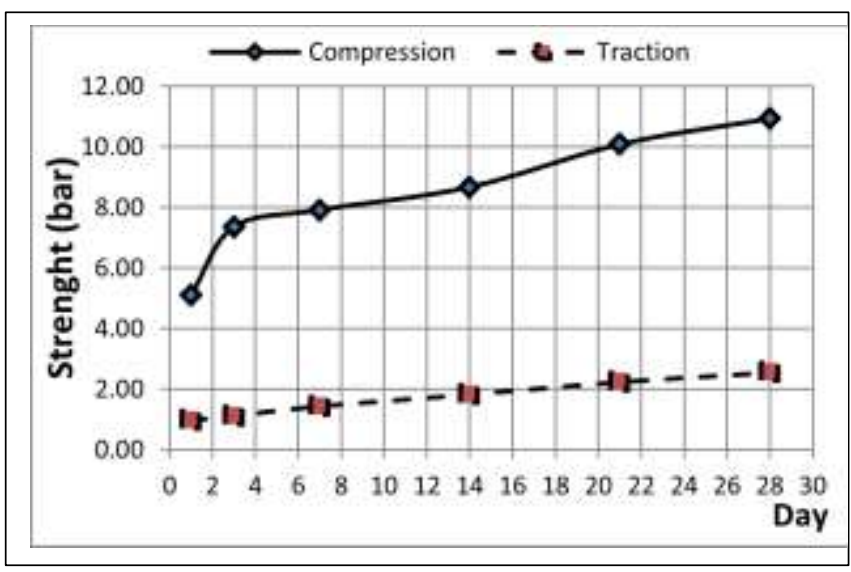

\section{Strength/dosage curve}

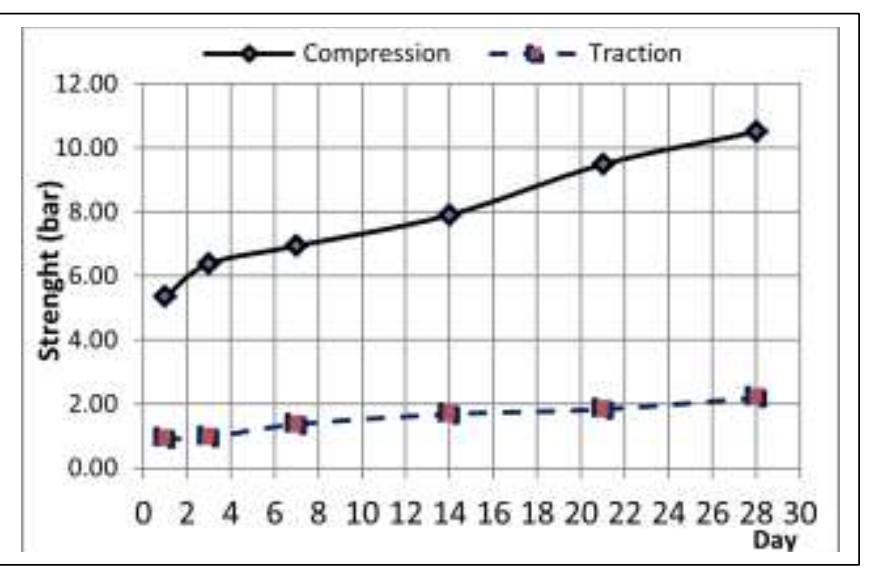

Strength/dosage curve

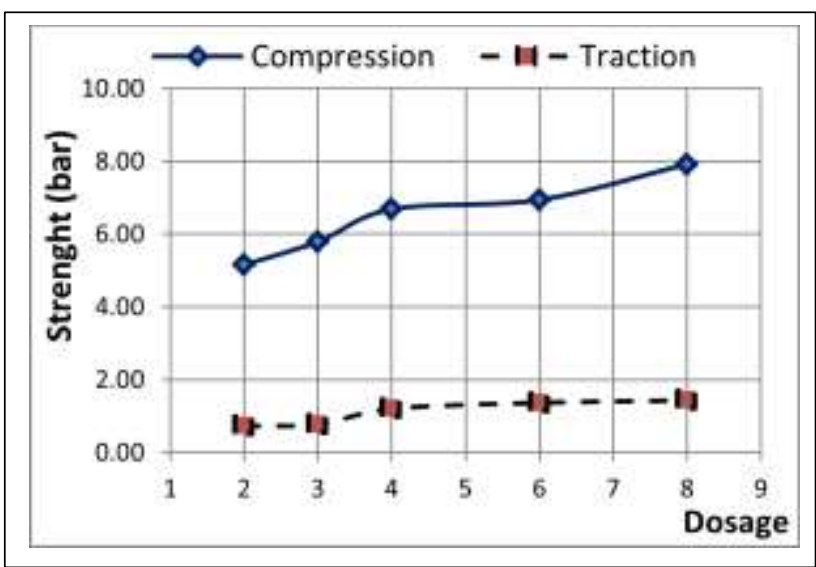

Fig. (12):- Evolution of the traction and compressive strength with age and percentage of lime

\section{Discussions:-}

The tudy of the material corrected with lime was a success since it has brought out the required modifications of the physical and mechanical properties of the material studied. It is observed that at up to $6 \%$ lime the material witnessed a net amelioration of its IBR, CBR, compression and traction strength. However the CBR index suffered a slight reduction which can be explained by the presence of too much lime. For economic reasons therefore it is not good to exceed the optimum dosage. It is worth noting that these performances may be influenced by the conditions under which the tests were carried out and instrumental limitations. As concerns condition, the treatment with lime is influenced by the treatment time and climate.

\section{Base course.}

The correction is convenient for the base course above all because the base course is not exposed to adverse external conditions. It receives a polished coat before the synthetic layer, this polished coat acts as a binder between the base course in stabilized material and the synthetic layer. It will be good to take special precautions to take care of the effect of treatment.

\section{Surface course:-}

At this level, it suffices to take construction dispositions to respect the exigencies of IAAF. Even if all the exigencies cannot be met, it shall be necessary that the layer resist to some environmental factors like erosion. Some of the dispositions are :

- Realization of this layer during the dry season to avoid modifications of the characteristics of the layer by rain water. 
- $\quad$ Finish with the works on this layer at least 3 months before the rainy season and the putting into use in order to assure that the treated material attains some level of resistance at long term or within its life span to face adverse climatic conditions, mechanical abrasion caused by the studs of the shoes of the athletes and their athletic poles or sticks.

The curves presented on figure 13 and 14 have been elaborated with the goal of determining the dosage on the basis of performance obtained with respect to the targeted layer.

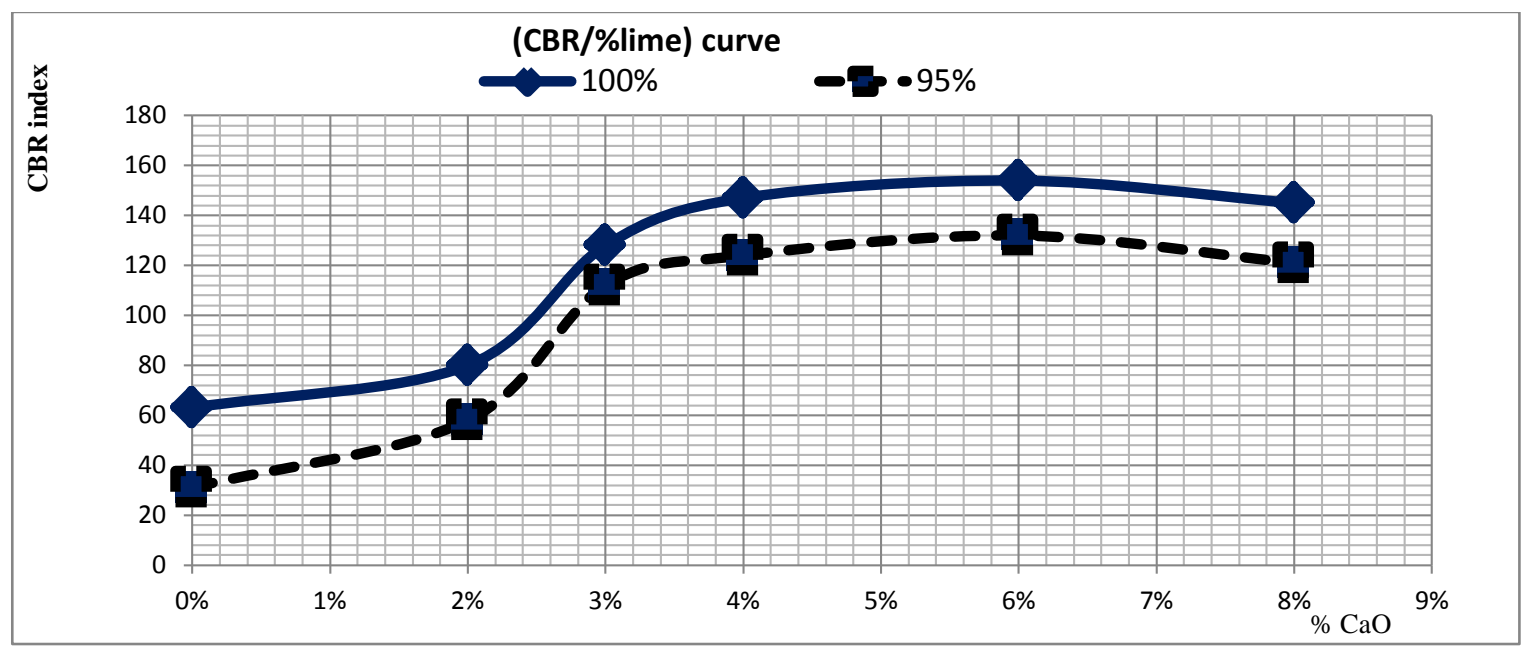

Fig. (13):- Variation of CBR with the percentage of lime.

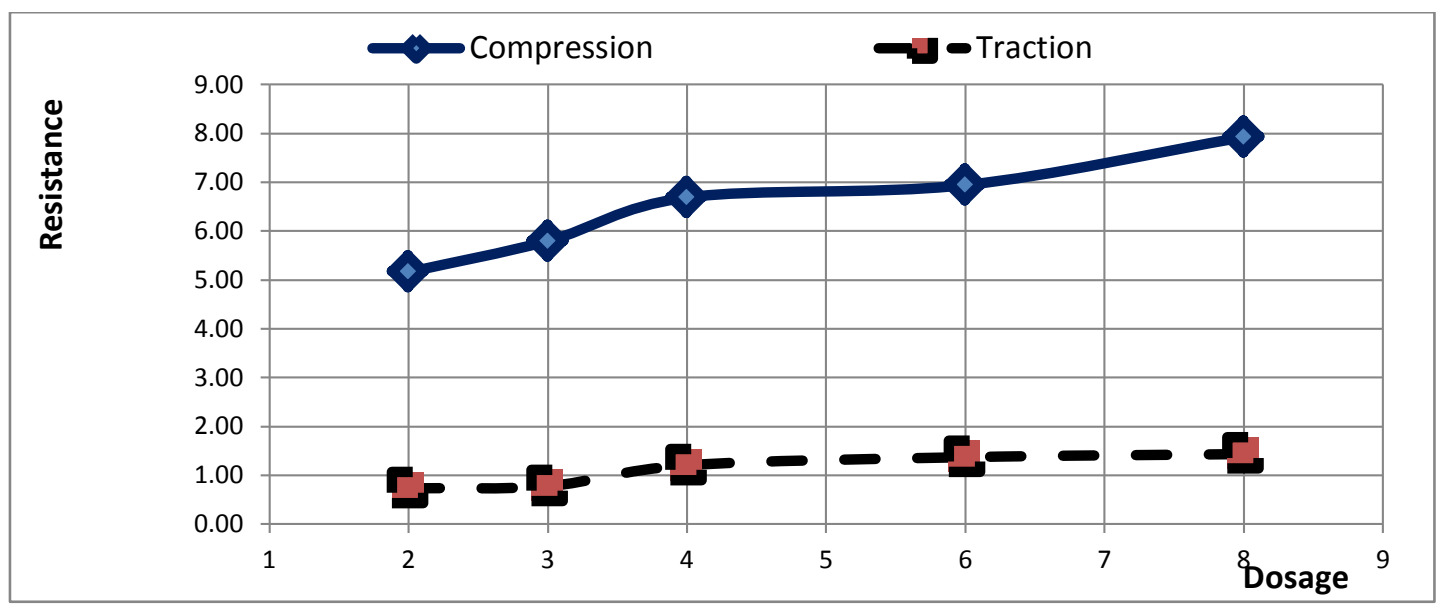

Fig. (14):- Variation of compressive and traction strength with the percentage of lime

\section{Dosage for the base course:-}

Since this layer shall not be over exposed to loads and climatic conditions, a proportion of $3 \%$ lime is enough (under such proportion, the CBR and IBR exceed 80 and 50 respectively). The performances attained suffice for it to resist the weight of the athletes and other eventual climatic conditions. Particular attention should be taken so that the layer does not suffer imperfections during the realization.

\section{Dosage for the surface course:-}

This layer shall be exposed to many adverse factors like the weight of the athletes, climatic conditions (runoffs and other discharges), penetration of the studs of the athletes, etc. In order to face these factors, it will be necessary that this layer has a better punching and shearing strength to avoid premature crackings. A good proportion of lime is also necessary to stabilize the material. A proportion of $4 \%$ lime is enough for the correction. The construction dispositions cited above must also be taken in to account. For this layer, with respect to temperature, the proportion 
of lime was chosen considering the evolution of plasticity index with the lime in order to avoid the premature crackings.

\section{Conclusion:-}

In its natural state, the silty sand studied does not respond entirely to the exigencies of soils required for sporting tracts. The correction of the studied material with lime was carried out in order for it to be used as sporting tracts. The silty treated with $3 \%$ lime can be used as a base course for sporting tracts. The material can resist all the stresses coming from the sporting activities. It suffices to apply a binding coat or fluidified bitumen to assure adherence between the base course and the synthetic surface in the case of international competitions so as to permit the athletes to have the same conditions of comfort. A good drainage system to evacuate water is imperative. With these precautions this structure can last for as long as possible if it didn't suffer imperfections during its execution.

\section{Reverences:-}

1. $\quad$ NF P 18-560, "Analyse granulométrique par tamisage", AFNOR, 9 p., 1978.

2. NF P 94-057, "Analyse granulométrique des sols, méthode par sédimentation", AFNOR, 17 p., 1992

3. NF P 94-051, "Détermination des limites d'Atterberg", AFNOR, 15 p., 1993.

4. NF P 18-597, "Détermination de la propreté des sables: équivalent des sable à $10 \%$ de

5. NF ISO 14235, "Qualité du sol-dosage du carbone organique par oxydation sulfo-chronique", AFNOR, 1998.

6. NF P 94-093, "Determination des références de compactage d'un matériau", AFNOR, 18 p., 1999.

7. NF P 94-078, "Indice CBR après immersion-Indice CBR immédiat-Indice portant immédiat", AFNOR, 12 p., 1997.

8. LCPC-SETRA, "Guide technique de conception et de dimensionnement des chaussées", AFNOR, 260 p., 1994. 